\title{
Tecnologias Móveis: Laptop XO e suas Contribuições para o Ensino de Música na Escola
}

\author{
Jaiane Ramos Barbosa ${ }^{1}$, Tereza Cristina Dourado Carrah Vieira Carvalho ${ }^{2}$ \\ ${ }^{1}$ Núcleo de Tecnologia Educacional - Secretaria de Educação de Maracanaú, CEP \\ 61.905.210 - Maracanaú - CE - Brasil \\ ${ }^{2}$ Escola Municipal de Ensino Infantil e Ensino Fundamental Professora Francisca \\ Florência da Silva \\ jaiane@virtual.ufc.br, tiaterezadourado@gmail.com
}

\begin{abstract}
This research deals with a study on actions taken in the integration between music and technology through the use of laptop. The aim is to describe the experiences of children from child to 5th grade of elementary school in the relationship between music education and technology of XO laptops through the TAM TAM MINI game as a new tool in the process of teaching and learning. The applied methodology was developed through a qualitative approach of action research. It was concluded that the integration between music and technology has provided benefits to project participants children, such as concentration, pleasure, learning,harmony, interaction, among others, in addition to computing the appreciation by all sectors of the school community. As future work we intend to expand the project with the use of mobile technologies like tablets and smartphones.
\end{abstract}

Resumo. A presente pesquisa aborda um estudo sobre ações desenvolvidas na integração entre música e tecnologia através do uso dos laptops. O objetivo é relatar as experiências vividas por crianças do infantil ao $5^{\circ}$ ano do ensino fundamental na articulação entre a educação musical e a tecnologia dos laptops XO,através do jogo TAM TAM MINI como uma nova ferramenta no processo de ensino e aprendizagem. A metodologia aplicada foi desenvolvida por meio de uma pesquisa-ação de abordagem qualitativa.Concluiu-se que a integração entre música e tecnologia proporcionou beneficios para as crianças participantes do projeto,como:concentração, prazer, aprendizado, harmonia,interação,dentre outros, além da valorização da informática por todos os setores da comunidade escolar.Como perspectivas de trabalhos futuros pretendemos ampliar o projeto com o uso de tecnologias móveis como tabletes e smartphones.

\section{Introdução}

Os avanços tecnológicos ocorridos nas últimas décadas acarretaram constantes transformações sociais. Dentre os diversos setores, influenciados pela chegada e permanecia da tecnologia em nossas vidas, o setor educacional merece destaque por possuir diversos aparatos tecnológicos que são comumente encontrados no ambiente escolar, criando assim a necessidade de uma maior adaptação das práticas pedagógicas à incorporação dessas tecnologias ao processo de ensino e aprendizagem.

Sobre isso, Gabriel (2013, p.9) enfatiza que a evolução tecnológica transforma profundamente a sociedade em todas as suas dimensões, inclusive na educação. A 
hiperconexão e a disponibilidade de acesso a conteúdos modificou a forma como as pessoas aprendem e obtêm informações.

Nessa perspectiva, os sujeitos pertencentes a essa geração constantemente fazem uso das Tecnologias Digitais da Informação e Comunicação (TDIC) destinadas ao consumo e produção de informações, compartilhamento de ideias, opiniões, diversão, estudo e criação de conteúdos virtuais. No entanto, quando relacionamos o uso das TDIC ao ambiente educacional, como instrumento facilitador da aprendizagem, sua frequência de uso é reduzida pelos educadores. Ao analisarmos o novo perfil dos educandos, entendemos que as escolas, também, devem acompanhar esses avanços e transformações.

Nessa perspectiva, percebemos a necessidade de uma transformação no modo de ensinar e, consequentemente, de aprender dos sujeitos envolvidos no processo de aprendizagem. Tendo em vista essa realidade, indagamos sobre qual seria o verdadeiro motivo da reduzida utilização dessas tecnologias na escolar durante os processos de ensino e aprendizagem? Já que historicamente, no Brasil, existiram diversos projetos governamentais que incentivaram o uso das mídias e tecnologias digitais na educação atrelados à formação de professores e distribuição de equipamentos.

Sobre isso, vários autores apontam para as necessidades educacionais em atender as especificidades de uma sociedade em constante transformação, imersa nas relações criadas pela presença e uso das tecnologias digitais (FAGUNDES,2008; ALMEIDA, 2000; VALENTE, 2002). Desse modo, a presente pesquisa objetiva apresentar o projeto intitulado Música e tecnologia na escola, desenvolvido em uma escola contemplada com a doação dos laptops, participantes do pregão, do projeto Um Computador por Aluno (UCA), e sua contribução para a incorporação das tecnologias móveis ao processo de ensino e aprendizagem.

\subsection{Como tudo começou}

O Projeto UCA baseia-se na proposta da Organização One Laptops per Children (OLPC), administrada por Nicholas Negroponte, com missão de distribuir laptops de baixo custo, do tipo XO, a fim de promover a inclusão digital de crianças pertencentes a países subdesenvolvidos ou em desenvolvimento. Experiências utilizando esse tipo de laptop já vinham sendo realizadas em outros países, como Portugal, Espanha, Paraguai, Argentina, Uruguai e Estados Unidos da América (BRASIL, 2008).

No Brasil, essa proposta foi apresentada, no ano de 2005, ao então presidente do país, durante sua participação no Fórum Econômico Mundial de Davos, na Suíça. A concepção do Projeto UCA no governo brasileiro tomou como base o projeto da OLPC, mas adequou sua proposta à inserção dos laptops ao contexto educacional.

Sobre esse fato, e de acordo com Castro Filho, Silva e Maia (2015) o advento das tecnologias móveis nas escolas brasileiras, impulsionado pelo surgimento do Projeto Um Computador por Aluno (UCA), proporcionou experiências pedagógicas inovadoras e desvelou novas possibilidades para a educação. Nesse sentido, como uma dessas possibilidades, no dia 14 de maio de 2015, à Secretaria Municipal de Educação do Município de Maracanaú do Ceará recebeu a quantidade de 470 laptops, em forma de doação. Os laptops foram enviados pela Escola Estadual Carneiro de Mendonça, mediados pelo Instituto UFC virtual e uma professora do NTM de Maracanaú que participou como formadora do projeto no Estado durante as fases destinadas ao projeto e programa UCA.

A partir dessa doação, 13 escolas de Ensino Fundamental I foram contempladas com 25 unidades de laptop a serem utilizados no modelo de laboratório móvel.Esse modelo de uso foi sugerido e implementado por todas as escolas devido a quantidade 
significativa de máquinas recebidas. Inicialmente as escolas foram visitadas pelos técnicos do Núcleo de Tecnologia Educacional objetivando esclarecer informações sobre a doação, formação e uso dos laptops, até então tecnologia nova nas escolas do município. Posteriormente, os professores lotados nos Laboratórios de Informática Educativa (LIE) receberam uma formação específica destinada ao uso pedagógico e de acordo com o sistema operacional presente nos laptops. No entanto, limitações referentes à infraestrutura de algumas salas de aula impossibilitaram a mobilidade do equipamento restringindo seu uso basicamente ao LIE. Esse foi o caso da escola cuja experiência exitosa apresentaremos a seguir.

\subsection{O projeto}

A Escola Municipal de Ensino Infantil e Ensino Fundamental Professora Francisca Florência da Silva, localizada no bairro Siqueira, foi uma das escolas contempladas com a doação dos laptops . Logo após uma das primeiras oficinas ministradas pelo Núcleo de Tecnologia Educacional de Maracanaú (NUTEM) acerca das possibilidades de uso pedagógico dos programas disponíveis no sistema operacional Linux Suggar de abordagem progressista pouco conhecido no país, vislumbrou - se a ideia de inserir o laptop nas atividades curriculares da escola.

Diante dessas possibilidades e apoiados na lei $\mathrm{n}^{\mathrm{o}} 11.769$ de 18 de agosto de 2008, que preconiza a música como conteúdo obrigatório, foi criado o projeto intitulado "Projeto Música e Tecnologia na Escola", o qual objetivava promover a educação musical neste novo ambiente de prática educacional mediado pela presença das tecnologias móveis apoiados pelos softwares de abordagem construtivista disponível nos laptops . Ou seja, promover o estudo da música de forma interdisciplinar associado à tecnologia.

De acordo com Acampora (2014) os benefícios da música na educação aumentam a inteligência auditiva e ajuda no desenvolvimento integral da criança. No setor neurológico, os estímulos musicais também podem facilitar o desenvolvimento linguístico e motor.

Entendendo essa importância, nas próximas sessões serão explanadas as experiências de como se deu a articulação entre a educação musical e a tecnologia dos laptops $\mathrm{XO}$, por meio do software TAM TAM MINI com alunos e professores da escola contemplada. Apresentaremos também, a metodologia, seguida de uma detalhada descrição do projeto desenvolvido. Posteriormente, serão expostos os resultados obtidos, enfatizando os eventos e experiências vivenciadas pelos alunos e professores a partir do início do projeto.

\section{Metodologia}

A metodologia aplicada foi desenvolvida por meio de uma pesquisa-ação de abordagem qualitativa. De acordo com Severino (2007) "a pesquisa-ação é aquela que, além de compreender, visa intervir na situação, com vistas a modifica-lá” (p.120). Nesse sentido, ao mesmo tempo que a pesquisa é realizada e analisada ela propõe um aprimoramento de suas práticas correlacionadas ao uso do laptop no ensino de música e os resultados dessa ação.

\subsection{Local e participantes}

Inicialmente a pesquisa foi realizada no segundo semestre de 2015 com as turmas dos turnos manhã e tarde do $5^{\circ}$ ano do Ensino Fundamental da Escola da PFFS, localizada no município de Maracanaú, no estado do Ceará. No primeiro semestre de 2016 o projeto englobou todas as turmas da escola, do infantil ao ensino fundamental I. 
O projeto teve até o momento duração de 8 meses. Durante esse período foram realizados encontros de ensaios periódicos duas vezes por semana. A partir do segundo semestre de 2015 e até final do primeiro semestre de 2016, os alunos participaram de 12 eventos culturais e institucionais, sendo 7 externos, ou seja, fora da escola e 5 eventos dentro da própria escola. Devido aos resultados positivos do projeto no meio docente e discente os alunos o projeto continua em andamento com perspectiva de renovação a cada semestre.

O projeto Música e tecnologia na escola é coordenado pela professora do LIE e conta com a participação direta dos discentes e indireta do corpo docente, núcleo gestor e comunidade. Todos os sujeitos participaram no suporte e apoio ao projeto.

O projeto envolveu além do estudo de música e da própria tecnologia, o ensino de LIBRAS, Português, Literatura, Artes, História e Matemática, favorecendo a apropriação tecnológica, inclusão digital e formação cidadã.

\subsection{Materiais usados}

Durante o desenvolvimento da pesquisa, utilizamos como instrumentos principais o laptop, o software TAM TAM MINI, caixas de som, amplificadores e cifras alfabéticas para o teclado. O software TAM TAM MINI é um programa de exploração de música e som introdutório que pode ser usado por crianças a partir dos 2 anos até a adolescência. Foram utilizados também catálogos de cifras destinados a orientação dos alunos durante o manuseio do teclado. Esses catálogos foram construídos pela professora do LIE por meio do uso de um site que indicava as notas musicais, posteriormente transformava para as letras do laptop.

\subsection{Instrumentais de coleta de dados}

A observação e o registro permitem a inserção do investigador no ambiente da pesquisa. Nesse sentido, o acompanhamento das ações do projeto foram realizadas por meio das observações assistemáticas realizadas por professores, alunos, gestores, pais de alunos e formadores do NUTEM durante as apresentações ocorridas nos eventos. De acordo com a utilização da observação casual como método, foi possível realizá-la de forma organizada por meio das anotações, impressões e registro fotográfico. Nesse sentido, durante as ações do projeto, ocorreram conversas informais, registro de fotos e vídeos ao longo dos encontros, oficinas, ensaios e apresentações.

A partir das observações realizadas nos ensaios e apresentações, foi possível avaliar o impacto do projeto no cotidiano dos alunos, bem como da própria escola. A seguir, explanaremos mais detalhes sobre a implementação e execução do projeto.

\section{Resultados}

Após a chegada dos laptops, deslumbrou-se a necessidade de conhecer os programas disponíveis no mesmo, pois muitos deles apresentavam elevado grau de complexidade por serem de um sistema operacional desconhecido pelos professores. A partir disso, inicialmente, as escolas contempladas receberam do NUTEM uma formação que objetivava promover a apropriação tecnológica do laptop e seus programas. $\mathrm{Na}$ formação seguinte, foi ofertada uma oficina destinada a utilização do software TAM TAM MINI, objeto principal do nosso trabalho. A seguir, discorreremos sobre o processo de implementação do projeto e sua execução. 
V Congresso Brasileiro de Informática na Educação (CBIE 2016)

Anais dos Workshops do V Congresso Brasileiro de Informática na Educação (CBIE 2016)

\subsection{Implementação do projeto}

O software TAM TAM MINI (figura 1) é um programa que possibilita a compilação de instrumentos musicais por meio da criação de sons, melodias e músicas, capazes de proporcionar que aos alunos experimentem, explorarem e criem suas próprias melodias. Ou seja, ele é um programa básico que permite a execução de melodias simples, pois o teclado do laptop permite a simulação de um piano. Ele possui 2 partes: uma apresenta todos os controles semelhante a janelas de um orgão elétrico e a outra um banco de sons do cotidiano. No teclado do laptops as letras do Q ao U correspondem as 7 notas musicais agudas (do, re, mi, fa, sol, la, si), já as letras do $\mathrm{Z}$ ao $\mathrm{M}$ correspondem as notas graves e as letras $\mathrm{S}, \mathrm{D}, \mathrm{G}, \mathrm{H}$ e $\mathrm{J}$ e os números 2,3, 5,6,7 são sustenidos e bemois.

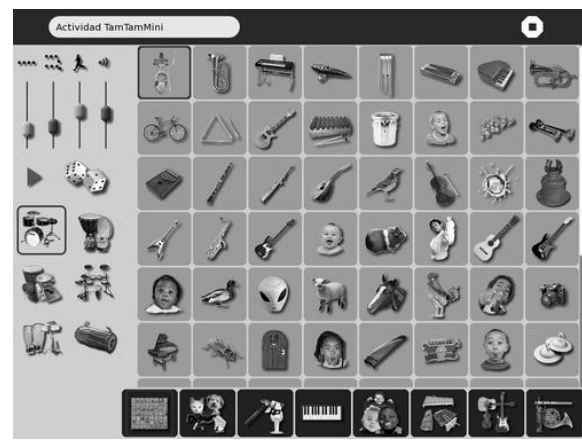

Figura 1 - Tela inicial do software TAM TAM MINI

Após participação na oficina sobre o software a professora do LIE idealizou e iniciou o planejamento do projeto na escola. Após a proposta ter sido aceita pela gestão da escola a mesma ministrou uma oficina de música para os alunos do $5^{\circ}$ ano do Ensino Fundamental I. Inicialmente foram escolhidos para fazer parte do projeto10 alunos, sendo 5 do período da manhã e tarde. De início os critérios utilizados para a escolha dos alunos foram: identificação do aluno com o objetivo do projeto, habilidade com o uso do teclado do computador, comportamento e compromisso durante as aulas. Os encontros aconteceram no LIE da escola durante o horário normal destinadas às aulas de informática da turma. Posteriormente os encontros passaram a ocorrer no contra turno.

Para que as crianças tocassem músicas nos laptops era necessário conhecer o alfabeto e a localização das letras no teclado, pois cada letra é correspondente a uma nota musical. Nesse sentido, nos encontros iniciais do projeto foi abordado fundamentos de teoria musical, apresentado as semelhanças e diferenças da tecnologia do laptop com o teclado musical. Em seguida, iniciou-se o treinamento da habilidade dos alunos ao dedilhar o objeto.

Para auxiliar esse processo, fora necessário a criação de um material impresso com canções sugeridas pelos alunos. Várias pesquisas foram feitas até descobrir um site que traria com maior facilidade cifras que pudessem ser transformar em notas alfabéticas para o laptop. Essa transformação foi realizada pela professora do LIE, pois nesse início de projeto os alunos necessitavam ter em mãos as partituras das músicas com as cifras transformadas em letras do teclado para serem tocadas nos laptops.

Vale ressaltar, que para que essa transformação fosse realizada foi necessário que a professora tivesse conhecimento em teoria musical. Essa foi uma das características primordiais para que o projeto obtivesse êxito. Diante disso, se faz necessário citar Bellochio (2003) "Entendo que é preciso possibilitar formação, em educação musical, ao professor unidocente, por meio de atividades práticas e teóricas, acreditando na sua possibilidade de trabalhar da melhor forma possível junto aos seus alunos". (p.20-21). 
Destaca-se aqui a importância das formações dos professores, de ampliar o conhecimento sobre essa temática, na maneira como as instituições de educação devem realmente abordar a incorporação da música ao currículo bem como, a inserção da tecnologia capaz de proporcionar uma abordagem musical e tecnológica, consistente e de qualidade.

Depois de descoberta as notas no teclado e com as canções em mãos, as crianças conseguiram tocar as músicas conforme estabelecidas no catálogo e assim surgiu a melodia. Após trabalhada a melodia, foi necessário abordar a harmonia com os alunos, pois como já fora mencionado anteriormente, um dos objetivos desse projeto, era formar um grupo de alunos no estilo orquestra, no qual todos tocassem músicas, ao mesmo tempo e no mesmo ritmo. Contudo, essa foi a maior dificuldade encontrada pelos alunos durante o projeto.

O intuito da oficina não era somente levar os alunos a tocar músicas nos laptops, bem como apropriar-se da tecnologia móvel, mas ir além disso, mostrar o que poderiam aprender por trás de cada música, que ensinamentos a música transmitia, a bibliografia do autor, as partes da música, a teoria musical, o estilo da música, entre outros. Durante o projeto uma das músicas que marcou positivamente os alunos foi a música "Escravo de Jó". Ao final de cada encontro um dos alunos tocava a música no laptop, enquanto os outros passavam o copo, realizando a tradicional brincadeira.

Sobre isso os Parâmetros Curriculares Nacionais enfatizam:

Em todas as culturas as crianças brincam com a música. Jogos e brinquedos musicais são transmitidos por tradição oral, persistindo nas sociedades urbanas nas quais a força da cultura de massa é muito intensa, pois são fontes de vivências e desenvolvimento expressivo musical. Envolvendo gesto, o movimento, o canto, a dança e o faz-de-conta, esses jogos e brincadeiras são expressão da infância. (BRASIL, 1998, v.3,p. 71-72).

Vale ressaltar, diante disso, a importância dos momentos de descontração, brincadeiras, jogos e confraternizações durante os encontros do projeto, pois era uma forma de motivá-las diante dos ensaios e compromissos externos a escola que não faziam parte da sua rotina.

No início do projeto foram ensinadas músicas conhecidas por eles, com o passar do tempo foram inseridas no repertório músicas desconhecidas, mas que apresentavam aspectos histórico e culturais. Quando a música era desconhecida pelos alunos, primeiramente eles escutavam, depois pesquisavam sua história, cantavam várias vezes, para enfim, tocá-las no laptop. Durante os ensaios os alunos utilizavam fones de ouvido e só tocavam juntos após terem aprendido a música. Como o projeto teve início em outubro de 2015 os alunos aprenderam a tocar primeiramente canções natalinas objetivando as festividades do final do ano.

Sobre o trabalho com projetos na escola Almeida (2000) defende que é uma forma de facilitar a atividade, a ação, a participação do aluno no seu processo de produzir fatos sociais, de trocar informações, de construir conhecimento. O trabalho com projeto objetiva ir além das limitações do currículo escolar, pois é uma forma mais organizada de possibilitar a aprendizagem discente.

Após o período de apropriação, ficou fácil para os alunos tocarem várias canções no laptop. Alguns até nem precisavam mais do auxílio do catálogo de cifras.Essa rápida apropriação e engajamento dos alunos no projeto gerou reconhecimento dos meios envolvidos. O reconhecimento do projeto surgiu na forma de convites. Convites esses que oportunizaram aos alunos apresentarem-se em vários eventos do município.Ao final do ano letivo de 2015 as crianças participantes do projeto saíram da escola, pois a mesma ofertava somente até o $5^{\circ}$ ano. Dessa forma, o ensino fundamental II seria realizado por eles em outra escola. 
Com o sucesso do projeto no ano de 2016 surgiram novos desafios, começar o projeto com novos alunos. Dessa vez a oficina de música foi ofertada para todas as turmas da escola, desde a educação infantil ao ensino fundamental I. A oficina objetiva selecionar os alunos com maior aptidão para participar do projeto. Nesse ano, o projeto disponibilizou 20 vagas, 10 para o turno da manhã e 10 para o turno da tarde. Essa seleção foi necessária devido ao espaço limitado do LIE e a quantidade de equipamentos.

Novamente, foram estabelecidos critérios para selecionar os alunos que participariam dessa nova fase do projeto. Os critérios estabelecidos foram: conhecer o alfabeto, gostar de música, vontade de aprender a tocar algum instrumento musical, habilidade no dedilhar do teclado, rendimento escolar, bom comportamento durantes as aulas, compromisso, respeito aos colegas e professores e autorização dos pais.

A seguir, apresentaremos como ocorreu a execução do projeto na escola bem como a participação dos alunos em eventos institucionais externos devido ao reconhecimento adquirido e depoimentos de pais, alunos e professores sobre a importância do projeto para a escola e ambiente escolar.

\subsection{Execução do projeto}

A linguagem musical atrelada ao uso da tecnologia móvel do laptop possibilitou que os professores trabalhassem com seus alunos aspectos do currículo oculto e institucional da escola como o conhecimento, interação, envolvimento com o mundo, organização, respeito, dentre outros.

A realização do projeto não proporcionou apenas uma experiência intelectual, ou cultural, mas completa-se, através do seu domínio, com possibilidades de transformar sujeitos, ampliando suas formas de perceber, interagir, agir e pensar. Os resultados do projeto aconteceram de forma inesperada e intempestiva, através de convites para que os alunos participassem dos eventos educacionais e sociais promovidos pelo Município. Diante disso, esse tópico foi dividido em dois subtópicos: 1) O projeto em 2015; 2) O projeto em 2016 e seus depoimentos.

\subsubsection{O projeto em 2015}

Os alunos do projeto receberam através de uma das formações do NUTEM o primeiro convite para tocar no III Encontro de Informática Educativa de Maracanaú, cujo o tema do evento era "Construindo aprendizagem significativa com o uso das tecnologias digitais na educação". O III Encontro aconteceu no dia 16 de novembro de 2015, no auditório da Secretaria Municipal de Educação, no qual 5 crianças apresentaram canções natalinas. A participação nesse evento, foi além da apresentação das crianças, pois a professora do LIE apresentou um trabalho na seção de modalidade oral (figura 2). Durante a exposição todos os participantes ficaram maravilhados com os resultados e ansiosos para que todas as escolas do município fossem contempladas com os laptops. O evento foi organizado pela equipe do NUTEM e contou com a presença de várias pessoas ilustres da secretaria de educação, como o Secretário de Educação e Diretora de Educação. Essas presenças deram grande visibilidade ao projeto que estava sendo desenvolvido na escola. Segue abaixo a imagem referente a participação das crianças no evento. 


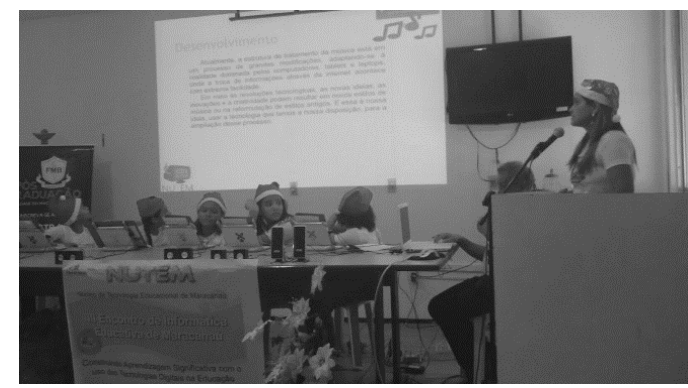

Figura 2 - Apresentação dos alunos no III Encontro de Informática Educativa

Após essa primeira apresentação externa os mesmos receberam convites para apresentar o projeto em vários eventos dentro do município, como na confraternização natalina dos professores de informática, confraternização natalina dos gestores escolares, no Seminário Municipal de Expectativas de Aprendizagens do $1^{\circ}$ ao $5^{\circ}$ ano do Ensino Fundamental durante três dias consecutivos e na própria escola dos alunos durante o I Recital de natal com laptops $X O$ que foi realizado como culminância do projeto.

É importante destacar que durante essas apresentações surgiram alguns desafios como tocar músicas desconhecidas e sem a cifra na internet, porém os desafios foram superados com a ajuda dos profissionais e parentes de professores envolvidos no projeto.

E para encerrar o ano de 2015 com êxito, foi desenvolvido na escola o I Recital de Natal com os Laptops XO. No recital as crianças tocaram canções natalinas dentre outras. Tiveram como público do recital, formadores do NUTEM como convidados, e os próprios alunos da escola, que puderam ver de perto o resultado final das oficinas ministradas. O objetivo do recital era valorizar o trabalho, o esforço e a dedicação dos alunos além de demonstrar o trabalho que estava sendo realizado. Tinha como objetivo também aguçar a curiosidade e despertar a vontade de outros alunos ingressarem no projeto no ano seguinte. Vale ressaltar, a importância que a música provoca na criança, um misto de alegria, prazer e emoção, comunicando-se com seus pares e com ela mesma. Ainda mais, essa música sendo tocada bem diferente da convencional, por meio de uma tecnologia móvel, com inúmeras tentativas de produzir sons cada vez mais atraentes e prazerosos.

Após a apresentação no recital, as crianças foram reunidas no LIE,onde puderam comemorar os resultados do que foi vivido e aprendido, com muita música, festa, comidas e premiações. Todas as crianças receberam uma pequena lembrança, para que essa experiência ficassem marcada para sempre na vida deles.

\subsubsection{O projeto em 2016 e seus depoimentos}

O sucesso do projeto durante o ano de 2015ocasionou reflexos positivos em 2016, pois o projeto ganhou bastante destaque no município. Então se fez necessário, logo que iniciada as aulas, selecionar novos alunos a participar do projeto. Nesse novo grupo foram escolhidos alunos do $3^{\circ}, 4^{\circ}$ e $5^{\circ}$ ano. E logo após a formação do grupo receberam o $1^{\circ}$ convite para participar da Ação Global. O Ação Global de Maracanaú foi realizado no dia 21 de maio de 2016 e tiveram a participação de 10 crianças, que tocaram 4 canções. Esse evento é de porte nacional, onde são realizadas um mutirão de cidadania que conta com apoio da TV Verdes Mares e Rede Globo de televisão.

Após a apresentação no Ação Global, os trabalhos não pararam, os alunos se apresentaram em mais 3 eventos, na festa do dia das mães e festa junina da própria 
V Congresso Brasileiro de Informática na Educação (CBIE 2016)

Anais dos Workshops do V Congresso Brasileiro de Informática na Educação (CBIE 2016)

escola, na cidade cenográfica do São João de Maracanaú (figura 4). Durante as apresentações juninas os alunos realizaram a sonoplastia do teatro do casamento matuto.

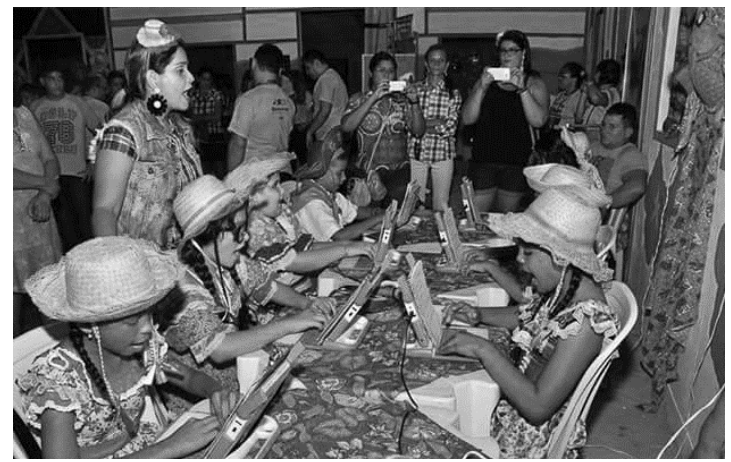

Figura 4 - Apresentação dos alunos na cidade cenográfica

Os resultados coletados revelaram que não só os professores da escola e gestores, mas toda a comunidade escolar reconheceu a importância da relação estabelecida entre música, criança, tecnologia e desenvolvimento com a realização do projeto, pois foram apontadas experiências interativas que puderam enriquecer essa relação.

A valorização do trabalho realizado também pode ser evidenciada através das postagens de pais de alunos e alunos nas redes sociais, como mostraremos a seguir:

Depoimento 1:"Eu como mãe da aluna, só tenho a agradecer por minha filha ter sido escolhida para participar desse evento. E saber que ela está aprendendo com pessoas maravilhosas (...) " (Depoimento da mãe da aluna L postado no facebook no dia 12/06/2016)

Depoimento 2: "Nosso quinto ano saiu ganhando...mais um aprendizado" (Depoimento da aluna R postado no facebook no dia 09/07/2016)

Dentre os dados coletados também foram evidenciados os depoimentos orais e escritos realizados pelos alunos de forma espontânea. Ao final de cada apresentação eles ansiavam pelo momento de compartilhar a experiência vivenciada com a plateia. Ao final do ano letivo as professoras da escola contempladas também fizeram relatos sobre a importância do projeto objetivando favorecer a ampliação do mesmo e ressaltar a sua relevância.

\section{Conclusão}

Diante de todos esses resultados o importante nesse projeto foi principalmente observar o interesse dos alunos pela música, bem como pela própria tecnologia em si, pois a união das duas proporcionou encantamento e alegria. Durante todos os encontros era notório o contentamento dos alunos ao utilizar os laptops. Quando os ensaios do projeto ocorriam no contra turno, não faltavam, chegavam no horário, ligavam os laptops , colocavam os fones e já começavam a ensaiar.

O desafio de ensinar música por meio do laptop revelou um saber fazer pedagógico-musical efetivo e substancial, pois revelaram um conhecimento científico atrelado a prática. As crianças puderam de forma lúdica, prazerosa e objetiva aprender sobre música e tecnologia. A realização do projeto, entre outras características,demonstrou que é possível que a educação musical ligada a uma tecnologia assuma um papel importante no universo das crianças assim como as outras linguagens.

Os dados revelaram também, que após o início do projeto, crianças com índices negativos em notas escolares e comportamento interpessoal melhoraram em relação aos 
índices apresentados antes do projeto. Esse dado se deu ao trabalho dos aspectos relacionados a concentração e harmonia, fatores benéficos no desempenho dos alunos. A observação desses aspectos foi notório devido a parceria estabelecida entre a professora de informática e da sala de aula e Atendimento educacional especializado (AEE).

O trabalho colaborativo e em parceria com professores, sala de AEE e gestores foi fundamental para o sucesso do projeto.Além disso, perceberam uma maior valorização de toda comunidade escolar do trabalho que estava sendo desenvolvido no laboratório de informática.Sabemos que com o passar do tempo, a educação escolar passou por profundas mudanças sociais que repercutiram no comportamento, estilo de vida, atitudes e valores, impactando na vida dos profissionais da educação e também dos alunos. Devido a essas mudanças, é preciso também atualizar o ensino para que as demandas atuais sejam atendidas. É preciso inovar! As tecnologias estão aí para isso e quando nos deparamos com ferramentas do tipo laptops que nos auxiliam de uma forma poderosa no processo de ensino e aprendizagem, percebemos a importância de como nós educadores precisamos estar em constante formação, buscando informações, integrando as tecnologias, para que possamos tornar nossas aulas criativas e dinâmicas.Como perspectivas de trabalhos futuros pretendemos ampliar o projeto com o uso de tecnologias móveis como tabletes e smartphones.

\section{Referências}

ALMEIDA, F.J.;FONSECA JÚNIOR,F.M. ProInfo: projetos e ambientes inovadores. Brasília: MEC, 2000.

ACAMPORA, Bianca. Guia Prático para professores de Educação Infantil. : http://www.revistaguiafundamental.com.br. Ano 10 - Edição 136 - Novembro/2014.

BRASIL. Referencial Curricular Nacional para a Educação Infantil. Ministério da: Educação e do Desporto, Secretaria de Educação Fundamental - Brasília: MEC/SEF, 1998. V.1: Documento Introdutório; v.2: Formação Pessoal e Social;v.3: Conhecimento de mundo.

Um Computador por Aluno: a experiência brasileira. Brasília: Câmara dos Deputados, Coordenação de Publicações, Série Avaliação de Políticas Públicas, no 1 , 2008. Disponível em: http://bd.camara.gov.br. Acessado em: 15/06/2016.

BELLOCHIO, C.R. Educação musical: olhando e construindo na formação e ação de professores. Revista da ABEM, Porto Alegre, n.6, p.41-47, set. 2001.

CASTRO FILHO, Jose Aires; SILVA, Maria Auricélia da; MAIA, Dennys Leite. (Orgs.). Lições do projeto um computador por aluno: estudos e pesquisas no contexto da escola pública. Fortaleza: EdUECE, 2015.

FAGUNDES, Léa. Diálogo, Tecnologia e Educação: A Diferença Entre Inovar e Sofisticar as Práticas Tradicionais. Revista Fonte, 2008, pp. 06-14. Disponível em: http://www.educacaoadistancia.blog.br/revista/dialogo.pdf. Acessado em: 18-07-2016.

GABRIEL, M. Educar: a revolução digital na educação. São Paulo: Saraiva, 2013 SEVERINO, A. J. Metodologia do Trabalho Cientifico. 23 ${ }^{a}$ ed. São Paulo: Cortez, 2007.

VALENTE, J. A. Repensando as situações de aprendizagem: o fazer e o compreender. Boletim do Salto para o Futuro, Brasília, 2002. 